\title{
Maximum power point tracking using perturb and observe, fuzzy logic and ANFIS
}

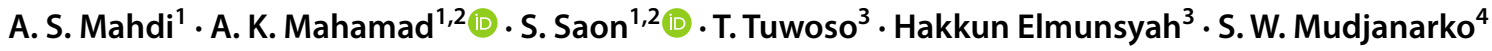

Received: 12 November 2019 / Accepted: 10 December 2019 / Published online: 16 December 2019

(c) Springer Nature Switzerland AG 2019

\begin{abstract}
The main objective of this project is to investigate the performance conventional method of perturb and observe (P\&O) and soft computing techniques (fuzzy logic and adaptive neuro-fuzzy inference system) of maximum power point tracking (MPPT) for photovoltaic (PV) module. In this paper, the MSX-64 PV module and boost DC-DC converter are used for simulation and modeling the MPPT system. This work demonstrates the performance of those three types of MPPT techniques, which subjected to a partial shading pattern as well as a non-shaded and shaded of real weather profile. These MPPT techniques are compare in terms of power extracted, MPPT efficiency, rise time, its ability to track global maximum power point (MPP), and the response to varied weather. Simulation results of soft computing MPPT techniques have shown the ability to track the MPP during partial shading conditions and the response to weather changes when nonshaded real weather profile applied to the system. The performance of the conventional P\&O based MPPT has depicted the failure of this controller to track the global MPP during partial shading and lack response to real weather changes. The proposed system has simulated using MATLAB SIMULINK.
\end{abstract}

Keywords Partial shading $\cdot$ ANFIS · Fuzzy logic $\cdot$ P\&O $\cdot$ MPPT

\section{Introduction}

The increased worries of nature and growing demand for energy as well as the world attention to global warming have induced thinking to find clean resources for energy, renewable energy that varies as wind, geothermal, hydro, solar and bioenergy. PV energy is one of such energy resources, which its importance has increased due to its inexhaustible nature, cleanness, scalability in power and low maintenance required [1].

There is a diversity of reasons that impact the amount of power generated by the PV array like atmospheric temperature, solar irradiation, the dust accumulated at the surface of the panel and the configuration of the electrical connection of the panels in the array. Considerably, power extraction and the efficiency of the PV system are affected by changing weather and partial shading conditions (PSC) [1]. By applying various approaches, the effect of the factors above on maximum power generation can be reduced; MPPT techniques are one of these approaches, it has employed to extract the maximum power and enhance the efficiency of the PV system. MPPT techniques have been implemented in both of the uniform irradiations and PCS [2].

Varieties of MPPT algorithms have been used and tested; the most common are fractional short circuit current, $\mathrm{P} \& O$, fractional open circuit voltage [3], hill climbing $(\mathrm{HC})$ algorithm [1] and incremental conductance (Inc. Cond.) [2]. Drawbacks of some algorithms such as the difficulty of implementation, overlook of the MPP during

$\triangle$ A. K. Mahamad, kadir@uthm.edu.my | ${ }^{1}$ Faculty of Electrical and Electronic Engineering, Universiti Tun Hussein Onn Malaysia, 86400 Parit Raja, Batu Pahat, Johor, Malaysia. ${ }^{2}$ Internet of Things Focus Group, Universiti Tun Hussein Onn Malaysia, 86400 Parit Raja, Batu Pahat, Johor, Malaysia. ${ }^{3}$ Universitas Negeri Malang, Jalan Semarang, No. 5, Blitar, Indonesia. ${ }^{4}$ Narotama University, Surabaya, Jawa Timur 60117, Indonesia. 
partial shading as well as low tracking speed have made the improvement of conventional techniques and rely on other methods that employ artificial intelligence (Al) is crucial for making the use of the PV system more effective.

$\mathrm{P} \& \mathrm{O}$ algorithm is a vastly used conventional technique to track MPP that is install in a commercial PV controller due to its simplicity. However, it has two drawbacks, these involve the oscillation at the vicinity of MPP, and that result in unending oscillation in output power. Consequently, reduced energy and lower efficiency will yield. The second drawback is the divergence from MPP when a sudden change in weather conditions occur and will fail to track MPP, which leads to a loss of energy [1]. Furthermore, to obtain an accurate MPPT algorithm, soft computing innovations like FL and ANFIS as an intelligent technique is chosen due to its capability to deal with the non-linear and non-exact mathematical model [2]. Some others MPPT method discussed previously are shown as in Table 1.

\section{Photovoltaic modeling}

The accuracy of the simulation is highly affected by PV module modeling. PV modeling includes estimation for the power-voltage $(\mathrm{P}-\mathrm{V})$ and current-voltage $(\mathrm{I}-\mathrm{V})$ characteristics curves for emulating the actual module at various weather conditions [3].

The PV module has been modeled by using the mathematical equations of single diode, $D$ model shown in Fig. 1 [8].

\subsection{Mathematical equations of solar cell}

The net output current from the PV module is given by Eq. (1) [8]

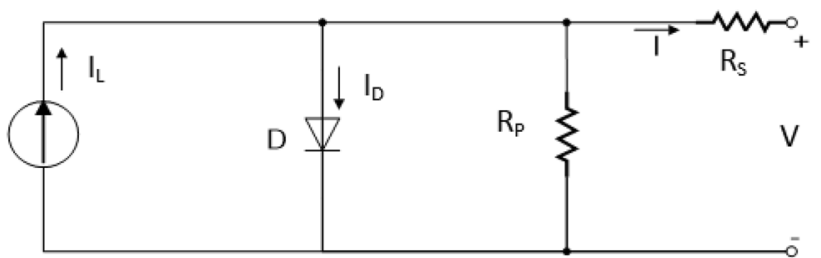

Fig. 1 Single diode modeling of solar cell [8]

$I=I_{L}-I_{D}-\left(V+R_{s} I\right) / R_{p}=I_{L}-I_{S}\left[e^{q\left(V+I R_{s}\right) / n k T}-1\right]-\left(V+R_{S} I\right) / R_{p}$

This is showing the relation between the current and the voltage of the module. The photogenerated current and diode saturation current is given by Eqs. (2), (3), and (4).

$I_{L}=\left[I_{s c n}+K_{i}\left(T-T_{n}\right)\right] G / G_{n}$

$I_{S}=I_{s n} *\left(T / T_{n}\right)^{3} \exp \left[q E g / n k\left(1 / T_{n}-1 / T\right)\right]$

$I_{s n}=I_{s c n} / \exp ^{\left(q V_{o c n} / n k T\right)-1}$

where, $I$ is output current, $V$ is output voltage, $I_{L}$ is photo current, $I_{D}$ is diode current, $I_{S}$ is reverse saturation current, $k$ is Boltzman constant, $q$ is charge of an electron, $T$ is actual temperature, $n$ is diode ideality constant, $R_{p}$ is shunt resistance, $R_{S}$ is series resistance, $I_{L n}$ is photocurrent at the nominal condition, $T_{n}$ is norminal temperature, $G$ is actual irradiation, $G_{n}$ is nominal irradiation, $I_{s c n}$ is norminal short circuit current, $V_{o c n}$ is nominal open circuit voltage, $E_{g}$ is bandgap energy, and $I_{s n}$ is nominal saturation current.

Table 1 Comparison of MPPT method

\begin{tabular}{|c|c|c|}
\hline MPPT method & Merits & Demerits \\
\hline Firefly algorithm [4] & $\begin{array}{l}\text { Faster convergence, high tracking efficiency, } \\
\text { never fall on local maximum power point }\end{array}$ & $\begin{array}{l}\text { Coefficient is updated in every iterations, which is } \\
\text { difficult to do }\end{array}$ \\
\hline Ant colony optimization [5] & $\begin{array}{l}\text { Simple control, low cost, robust to various shad- } \\
\text { ing condition pattern }\end{array}$ & Complex calculation \\
\hline Artificial bee colony optimization [6] & Simple, uses fewer control parameters & $\begin{array}{l}\text { Slow tracking, complex computation may fall on } \\
\text { local maximum power point }\end{array}$ \\
\hline Particle swarm optimization (PSO) [7] & Convergence speed and accuracy are better & $\begin{array}{l}\text { Excessive amount of calculation, computationally } \\
\text { complex }\end{array}$ \\
\hline $\mathrm{P} \& \mathrm{O}$ & Simple controller and low cost & $\begin{array}{l}\text { Failure to track the global MPP during partial } \\
\text { shading and lack response to real weather } \\
\text { changes }\end{array}$ \\
\hline FL system & Reduce response time of PV system & Computational complexity depend on the system \\
\hline ANFIS & High efficiency and high power & $\begin{array}{l}\text { Excessive amount of calculation, computationally } \\
\text { complex }\end{array}$ \\
\hline
\end{tabular}


Series and shunt resistances values used in modeling the PV are $0.221 \Omega$ and $415.405 \Omega$, respectively [9].

\subsection{Characteristic curves of PV module}

In this project, the Polycrystalline PV module MSX-64 with 36 polycrystalline silicon solar cells has been used;

Table 2 MSX-64 parameters under standard test conditions (STC)

\begin{tabular}{ll}
\hline Parameter & Value \\
\hline Maximum power $\left(P_{\max }\right)$ & $64 \mathrm{~W}$ \\
Voltage at $P_{\max }$ & $17.5 \mathrm{~V}$ \\
Current at $P_{\max }$ & $3.66 \mathrm{~A}$ \\
Short-circuit current $\left(I_{s c}\right)$ & $4.0 \mathrm{~A}$ \\
Open-circuit voltage $\left(V_{o c}\right)$ & $21.3 \mathrm{~V}$ \\
Temperature coefficient of short-circuit cur- & $(0.065 \pm 0.015) \% /{ }^{\circ} \mathrm{C}$ \\
$\quad$ rent & \\
Temperature coefficient of open circuit Volt- & $-(80 \pm 10) \mathrm{mV} /{ }^{\circ} \mathrm{C}$ \\
age & \\
\hline
\end{tabular}

the PV module parameters and values are shown in Table 2.

To emulate partial shading conditions to be studied in this project, the PV module has divided into three groups of 12 cells for each group. In such a way, each group receives a different level of irradiance, as shown in Fig. 2, and consequently, the performance of various MPPT techniques can be observed and compared during PSC. The levels of irradiance applied to the PV module are 1000,600 , and $300 \mathrm{~W} / \mathrm{m}^{2}$ and a constant temperature value of $25^{\circ} \mathrm{C}$ with each level of irradiance.

Characteristic curves of PV module MSX-64 during PSC are illustrated in Fig. 3, the effect of partial shading can be noticed from this figure as the presence of three MPP of values $16.196 \mathrm{~W}$ and $21.415 \mathrm{~W}$ and the global MPP of $25.967 \mathrm{~W}$.

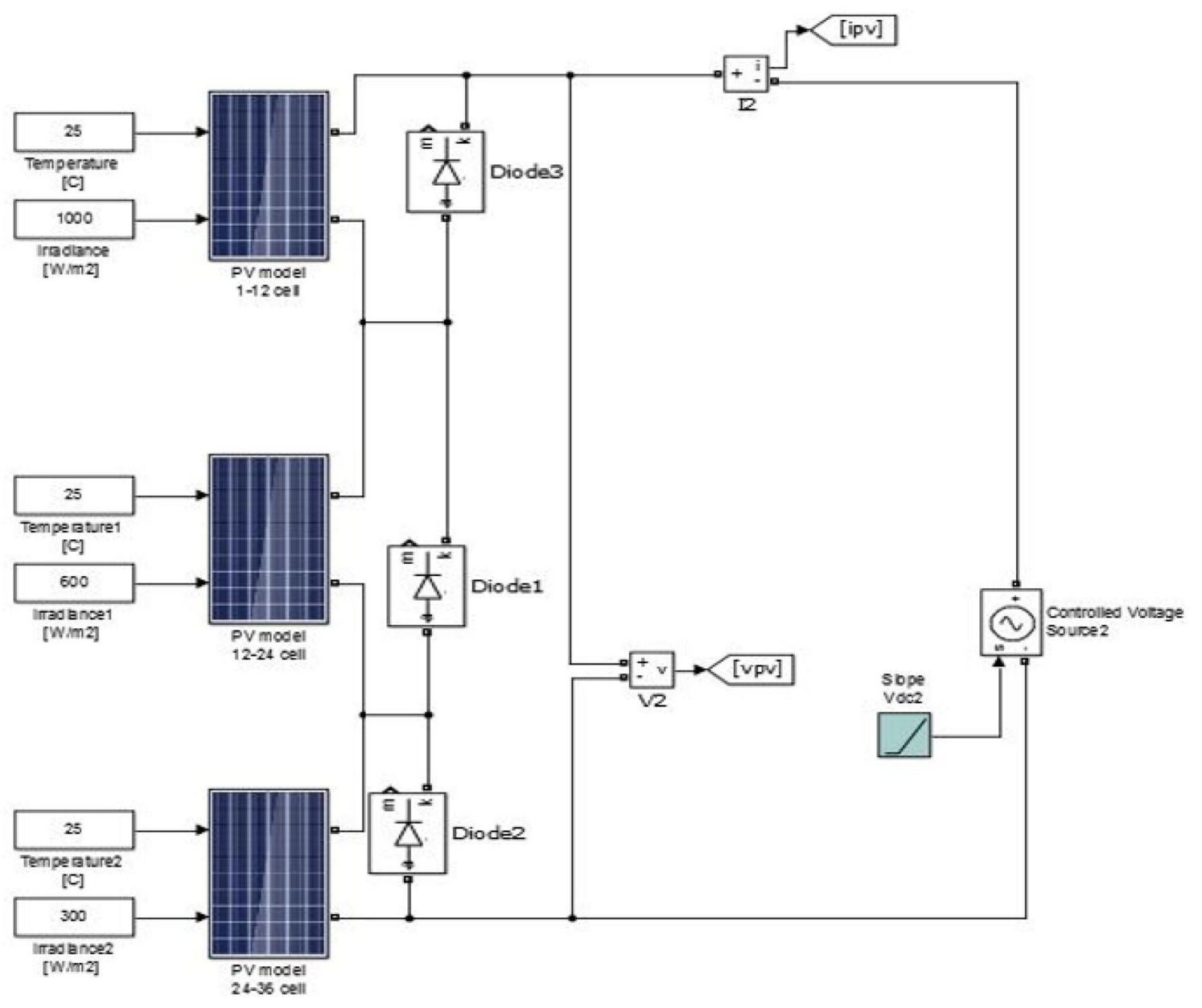

Fig. 2 Modeling of PV module during partial shading conditions 


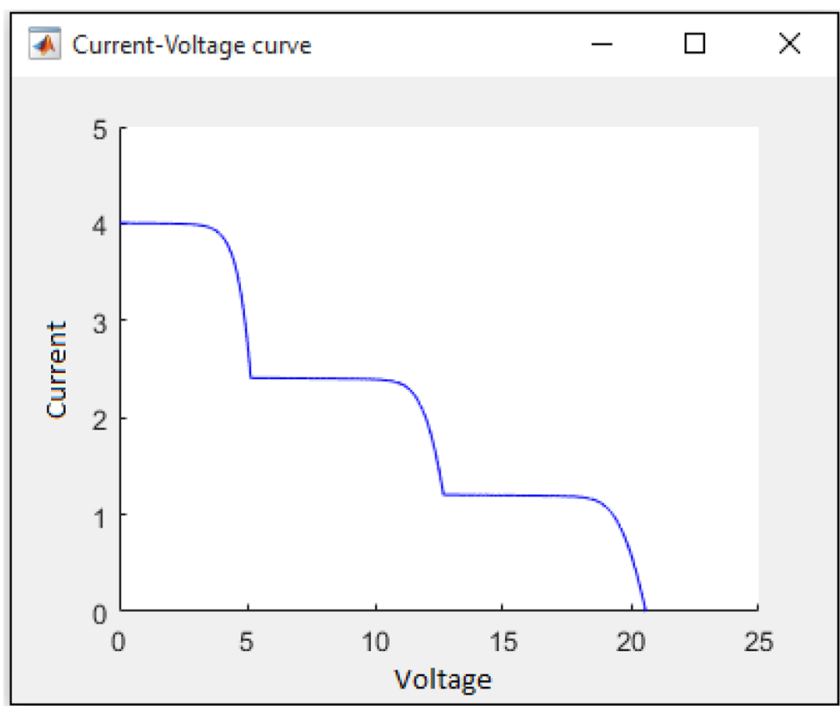

(a)

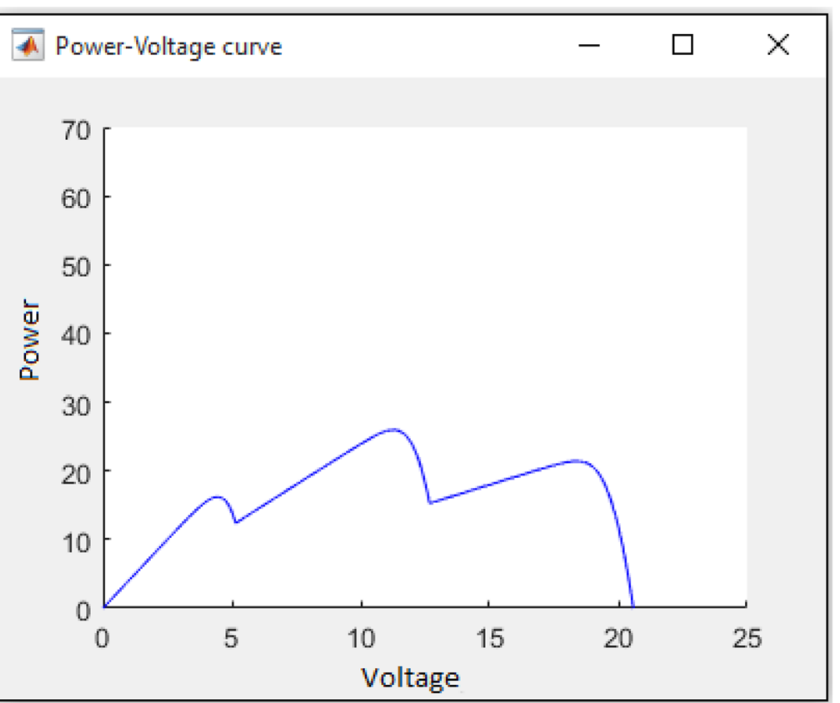

(b)

Fig. 3 PV characteristics curves during partial shading $\left[T=25^{\circ} \mathrm{C}, \mathrm{G}=(1000,600,300) \mathrm{W} / \mathrm{m}^{2}\right]$, a I-V and b P-V curve

Fig. 4 The overall project development flowchart

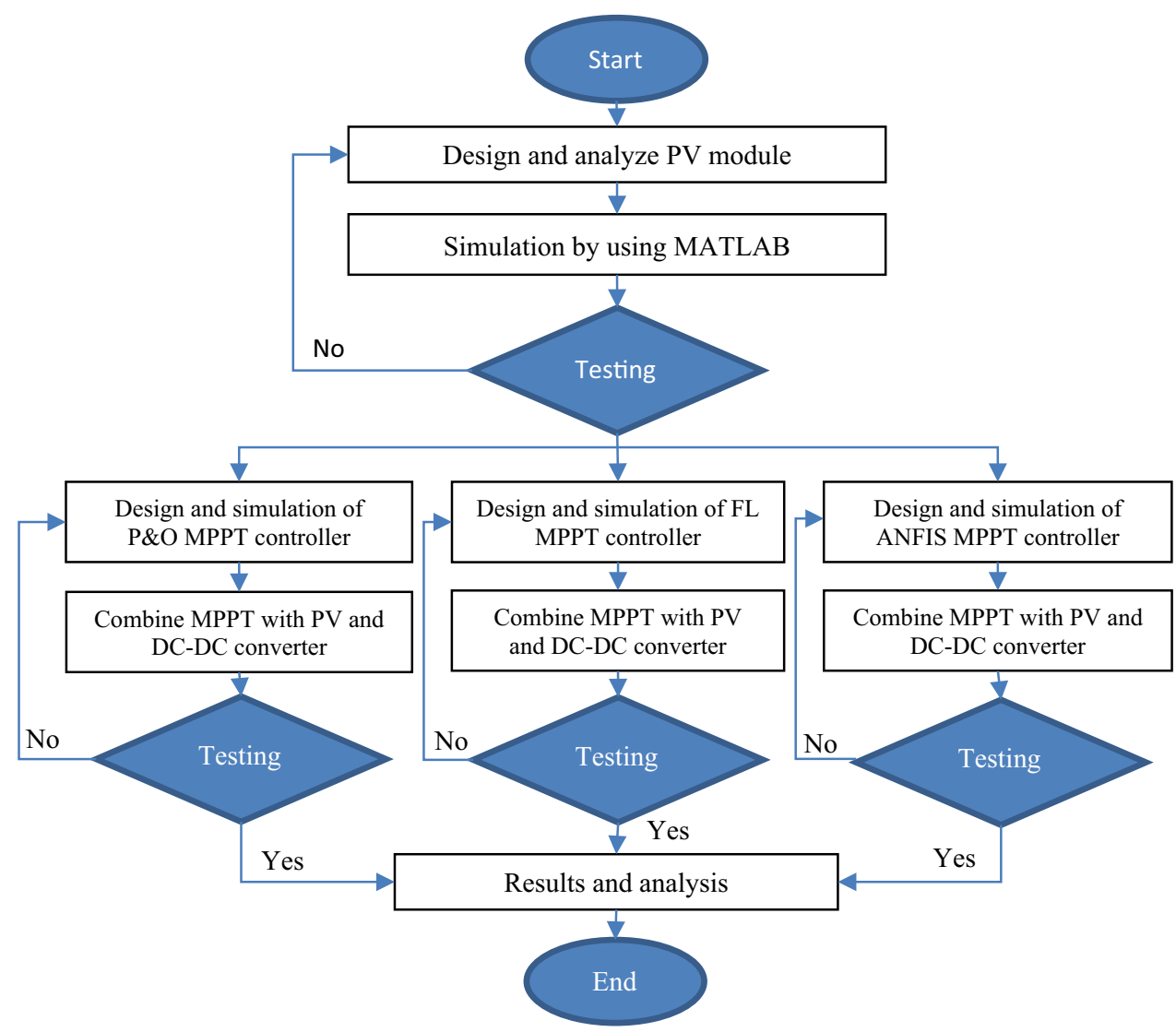




\section{Maximum power point tracking (MPPT) algorithms}

A specific type of PV modules has been chosen for PV modeling as well as three different MPPT techniques have used for maximum power extraction from the PV module, with overall development flow is shown in Fig. 4. The converter topology to transfer power from the source to the load is an essential part of this project that performs a significant function in the process of maximum power extraction together with the MPPT controller. By using MATLAB/ SIMULINK, the parts mentioned above are simulated and explained, and the performance of the MPPT controller is highlighted.

\subsection{Conventional perturb and observe ( $P \& 0)$ algorithm}

Perturb and observe algorithm includes a perturbation in the voltage and observing the power yield. By this technique, voltage incrementing cause the power to increase if the operation is on the left side of the MPP, and decreasing the power when it is on the right side of the MPP. To sum up, the above-mentioned process is illustrated in Table 3 [10].

The drawbacks of using this conventional technique are its failure to track MPP when there is a big change in the insolation level as well as the continues oscillation around MPP. However, this method is featured by its simple structure, simple implementation, and its lower cost [11]. The $\mathrm{P} \& \mathrm{O}$ algorithm flowchart is demonstrated in Fig. 5 [12].

Where, $V(k)$ is the current value of PV output voltage, $V(k)-1$ is the previous value of the PV output voltage, $I(k)$ is the current value of the PV current, $P(k)$ is the current value of the PV output power, $P(k)-1$ is the previous value of the PV output power and $V_{\text {ref }}$ is reference output voltage of the $\mathrm{P} \& \mathrm{O}$ controller.

\subsection{Fuzzy logic controller (FLC)}

FL has some advantages compared to other controllers, it does not require an exact mathematical model, and it can work with non-accurate input values and dealing

Table 3 P\&O MPPT algorithm summary [10]

\begin{tabular}{lll}
\hline Perturbation & Change in power & Next perturbation \\
\hline Positive & Positive & Positive \\
Positive & Negative & Negative \\
Negative & Positive & Negative \\
Negative & Negative & Positive \\
\hline
\end{tabular}

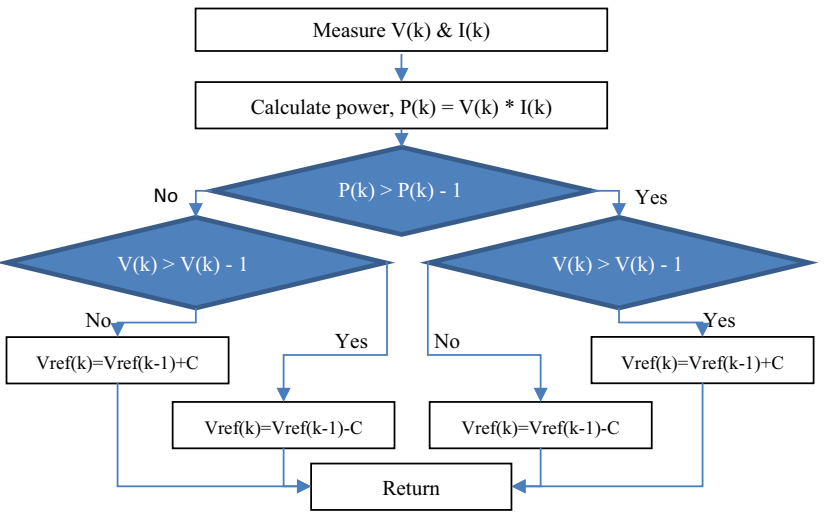

Fig. 5 Flowchart of P\&O MPPT technique [12]

with nonlinear systems. FL can compute the size of the perturbed voltage required to reach MPP [13].

The inputs of the proposed FLC are the change in power $(\Delta P)$ and change in the voltage $(\Delta V)$ and can be expressed in Eqs. (5) and (6), respectively.

$\Delta P=P(k)-P(k-1)$

$\Delta V=V(k)-V(k-1)$

The Mamdani method with Max-Min is used for the fuzzy combination, and the shape of the inputs and output membership functions in the proposed FLC is trapezoidal. For each input variable, there is five membership function, so the proposed FLC has contained 25 rules. The setting values of membership function have been selected by trial and error to obtain the best output values for the duty cycle. The linguistic variables are shown in Table 4, where $\mathrm{P}$ and $\mathrm{N}$ mean positive and negative, respectively, while $Z E, S$ and $B$, is zero, small and big, respectively. The numbers in the Table 4 refer to the 25 rules set.

To transform the output of the FLC into a crisp real value, the center of gravity has been chosen as a defuzzification method due to its being commonly used.

Table 4 Rule base of the FLC

\begin{tabular}{|c|c|c|c|c|c|}
\hline \multirow[t]{2}{*}{$\triangle \mathrm{PPV}$} & \multicolumn{5}{|l|}{$\triangle \mathrm{VPV}$} \\
\hline & NB & NS & ZE & PS & PB \\
\hline NB & PS (1) & PB (6) & NB (11) & NB (16) & NS (21) \\
\hline NS & PS (2) & PS (7) & NS (12) & NS (17) & NS (22) \\
\hline ZE & ZE (3) & ZE (8) & ZE (13) & ZE (18) & ZE (23) \\
\hline PS & NS (4) & NS (9) & PS (14) & PS (19) & PS (24) \\
\hline PB & NS (5) & NB (10) & PB (15) & PB (20) & PS (25) \\
\hline
\end{tabular}




\subsection{Adaptive neuro-fuzzy inference system controller (ANFIS)}

After simulating the PV module MSX 64 according to the specifications data of the manufacturer, training data are obtained for partial shading pattern and real weather profile [14].

To obtain training data for a non-shaded weather conditions, the process can be implemented offline without using any MPPT controller by applying various values of duty cycle to the boost converter and observing the output power of the PV module until it reaches the maximum value and records the corresponding duty cycle at specific input values for irradiance and temperature. This requires accuracy by varying the duty cycle from 0 until 1 to get the maximum output power to ensure proper training data. To be useable for ANFIS training, these data should have an array arrangement with three columns, where temperature and irradiance columns represent the inputs and the recorded duty cycle is the output of the ANFIS. The system is trained for 50 epochs, and the obtained training error is $1^{*} 10(-3)$.

Same procedures to obtain the training data is requested for $25 \%$ shaded irradiance profile, where irradiance level have shaded, and the temperature kept unchanged as shown in Fig. 7. This weather profile applied to the PV module as well as the ANFIS network which is trained to become learning model to get the desired output duty cycle for better tracking, which the network is trained for 20 epochs and obtained training error of $1.756 * 10(-5)$. The third test used to examine the performance of ANFIS tracking method by applying 50\% shaded weather to the system and same procedures as for non-shaded, and $25 \%$ shaded weather have followed to get the training data. The system is trained with 15 epochs and obtained training error of $6.9186 * 10(-8)$.

For simulation under PSC, the training data are obtained by simulate the PV module and measure the current, voltage and the corresponding output power during partial shading pattern. This data used as training data and part of this data used for checking purpose, which the input for the ANFIS are current and voltage, while power is the output of the controller. Subsequently, it become a reference power that compared with the output power of the PV module, which an error signal is produced and fed to the proportional and integral controller (PIC) in order to generate the suitable duty cycle. The system is trained for 10 epochs, and the obtained training error is $1.7 * 10(-7)$. Figure 6 shows the flowchart for the ANFIS based MPPT implementation [15].

\section{SN Applied Sciences}

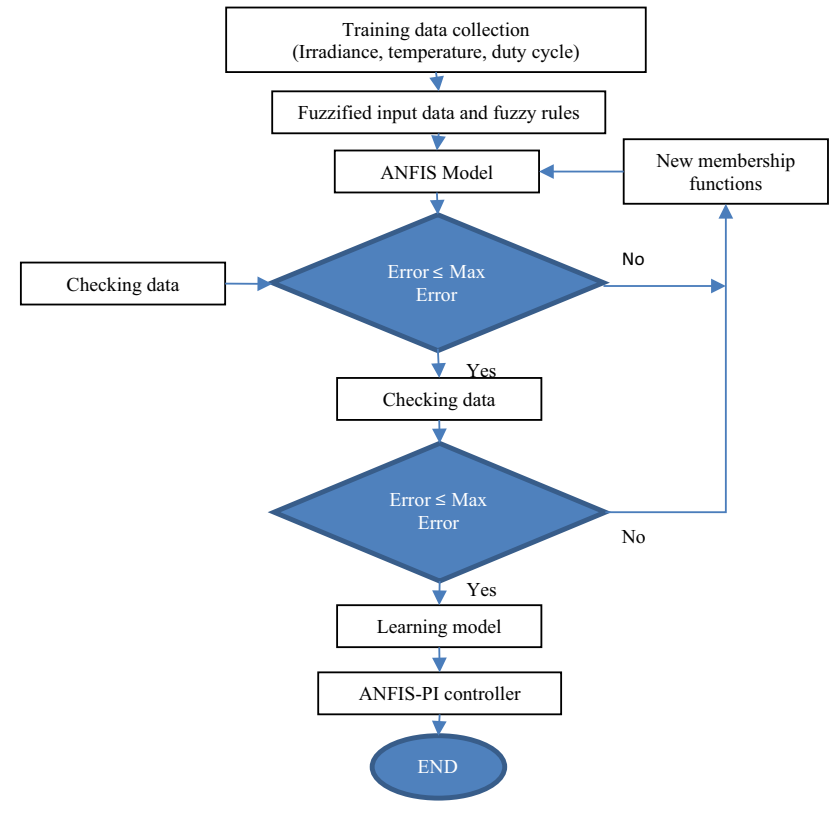

Fig. 6 Flowchart for the ANFIS MPPT algorithm [15]

\section{Simulation and results}

\subsection{System performance during PSC}

To compare the performance of the three MPPT controllers proposed in this study during PSC, the system is subjected to the partial shading pattern, and the three-controller response has compared accordingly. Simulation results of P\&O, FL and ANFIS controller when it subjected to PSC shows the average power of $19.79 \mathrm{~W}, 25.86 \mathrm{~W}$ and $25.96 \mathrm{~W}$, respectively.

\subsection{System performance under real weather conditions}

For validation purposes in real weather conditions, a real weather profile of irradiance and ambient temperature for $12 \mathrm{~h}$ have applied to the system at the non-shaded condition from 6 am to $6 \mathrm{pm}$ as shown in Fig. 7, for the simulation of the MPPT system performance. This weather profile has used to test the MPPT controller's response when it is shaded between 9 am to $3 \mathrm{pm}$ by a percentage of $25 \%$ and $50 \%$ respectively as shown in Fig. 7 and the response and performance of the proposed controllers have examined and compared.

The irradiance level has the significant effect on the PV output power, while ambient temperature has limited impact, as the surface temperature of the PV cell does not increase rapidly during PV system in daily operation, so it is kept unchanged during all testing cases. 


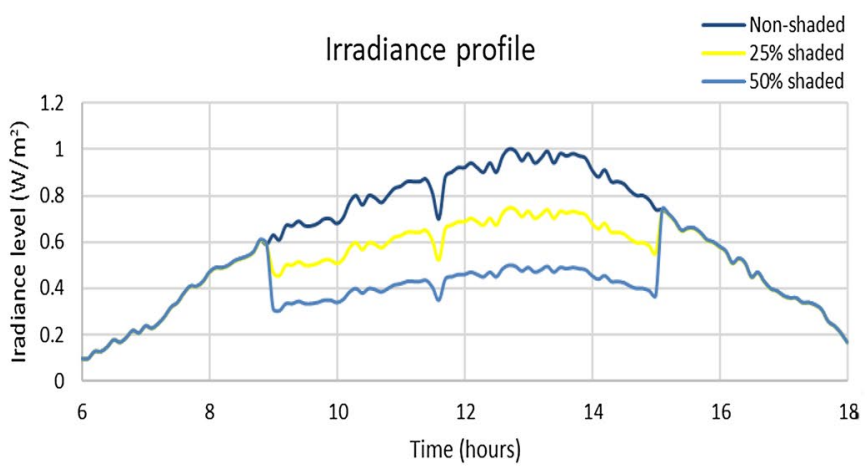

(a)

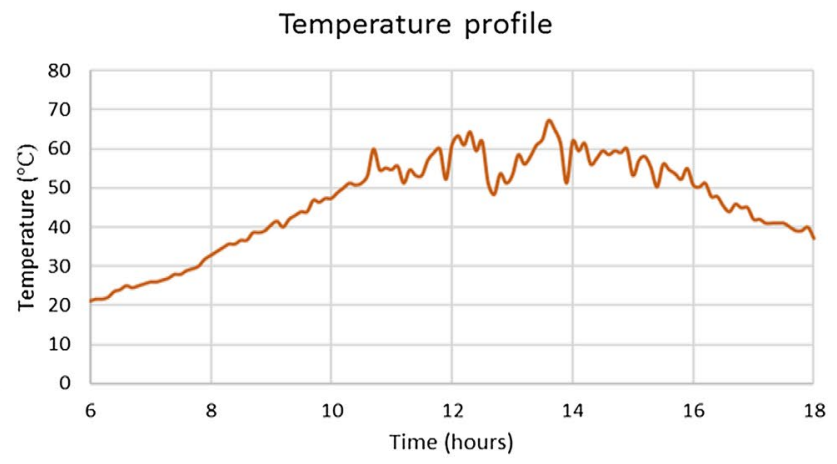

(b)

Fig. 7 Weather profile of $\mathbf{a}$ irradiance and $\mathbf{b}$ temperature

\subsection{System simulation with non-shaded irradiance level}

To test the MPPT system under real climatic daily weather, the system was subjected to the weather profile shown in Fig. 7 by using the non-shaded irradiance level and the ambient temperature profiles, and the response of the three controllers has examined and compared.

\subsubsection{P\&O controller}

Simulation results with P\&O controller shows the MPPT ability to respond to the variation in irradiation level and temperature at low irradiance levels, but it failed to respond to those changes as the level of irradiance increasing. Consequently, maximum power is not traceable at the maximum level of insolation. The maximum power extracted is $17.7 \mathrm{~W}$.

\subsubsection{FL controller}

The tracking response of the FLC shows the measured power waveform of the effectiveness of this controller to response to a slow weather change when a real weather profile with a slow variation of insolation and temperature levels is applied to the PV module. The power extracted is $63.57 \mathrm{~W}$ at the maximum level of irradiance.

\subsubsection{ANFIS controller}

ANFIS controller response under real weather condition with power waveform reveals the ability of this controller to respond to the slow variations of insolation level and ambient temperature after fine training for the network. The maximum power extracted by this controller is $63.72 \mathrm{~W}$.

In a nutshell, when contrasted to conventional, soft computing based MPPT techniques have shown superiority in performance under real weather conditions with a non-shaded PV system, where soft computing techniques are more stable and able to track the new MPP for the new irradiance levels. The efficiency of the MPPTs can be calculated by using Eq. (7).

$\eta_{M P P T}=P_{M P P} / P_{M P P_{*}} * 100$

where $P_{M P P}$ and $P_{M P P_{*}}$ are the maximum power extracted by using MPPT and PV module maximum output power, respectively. The performance benchmarking of MPPTs controllers can be summed up in Table 5 .
Table 5 Performance benchmarking for proposed MPPTs controllers under real weather conditions

\begin{tabular}{llllll}
\hline MPPT controller & $\begin{array}{l}\text { Maximum } \\
\text { power }(\mathrm{W})\end{array}$ & MPPT efficiency & $\begin{array}{l}\text { Average } \\
\text { power }(\mathrm{W})\end{array}$ & Rise time (ms) & $\begin{array}{l}\text { Response } \\
\text { to a varied } \\
\text { weather }\end{array}$ \\
\hline P\&O & 17.7 & 27.656 & 14.23 & 592.104 & No \\
FL & 63.57 & 99.328 & 36.75 & 2250 & Yes \\
ANFIS & 63.72 & 99.562 & 36.27 & 1789 & Yes \\
\hline
\end{tabular}


Table 6 Performance benchmarking for proposed MPPTs controllers

\begin{tabular}{llllll}
\hline MPPT controller & $\begin{array}{l}\text { Maximum } \\
\text { power }(\mathrm{W})\end{array}$ & MPPT efficiency & $\begin{array}{l}\text { Average } \\
\text { power }(\mathrm{W})\end{array}$ & Rise time (ms) & $\begin{array}{l}\text { Response } \\
\text { to a varied } \\
\text { weather }\end{array}$ \\
\hline $\begin{array}{l}25 \% \text { shaded irradiance profile } \\
\text { P\&O }\end{array}$ & 17.05 & 26.64 & 13.34 & 758.902 & No \\
FL & 52.56 & 82.125 & 30.7 & 1548 & Yes \\
ANFIS & 52.64 & 82.25 & 36.45 & 4491 & Yes \\
$50 \%$ shaded irradiance profile & & & & No \\
P\&O & 17.05 & 26.64 & 12.74 & 758.902 & Yes \\
FL & 48.65 & 76.015 & 23.4 & 1230 & Yes \\
ANFIS & 50.53 & 78.953 & 23.98 & 77.227 & \\
\hline
\end{tabular}

\subsection{System performance under $25 \%$ and $50 \%$ shaded irradiance profile}

\subsubsection{P\&O controller}

P\&O controller response with $25 \%$ shaded weather condition, shows that this controller is unable to respond to weather changes as irradiance and temperature levels increased while average power is kept almost unchanged, as well as the limited maximum power extracted of $17.05 \mathrm{~W}$. While, response of $50 \%$ shaded weather conditions shows a limited capability to keep tracking the change in weather variations and a low maximum power extraction, and consequently, a lower efficiency.

\subsubsection{FL controller}

The tracking response of FLC with $25 \%$ shaded weather condition shows the maximum power extracted is $52.56 \mathrm{~W}$ at the maximum level of irradiance reached. Meanwhile, response to $50 \%$ shaded irradiance profile shows the maximum power obtained is $48.65 \mathrm{~W}$. FLC has demonstrated a response to the changes in weather conditions by tracking the shaded irradiance and the temperature variations that may occur during the daily operation of the PV system.

\subsubsection{Adaptive neuro-fuzzy inference system controller}

The ANFIS controller response with $25 \%$ shaded weather condition is shows the power waveform reveals the ability of this controller to respond to the variations of shaded insolation and ambient temperature changes. The maximum power extracted by this controller is $52.64 \mathrm{~W}$. The performance benchmarking for the proposed MPPTs controllers under $25 \%$ and $50 \%$ shaded irradiance profile is shown in Table 6.

The extracted power waveform illustrates the response of the ANFIS controller to the weather changes and the shading effect on the PV system as well as the oscillation occurred during the tracking process for the applied shaded signal.

\section{Conclusion}

In this paper, three methods of MPPT techniques were proposed, $\mathrm{P} \& \mathrm{O}$ as conventional and FL as well as ANFIS as a soft computing technique, which these methods have designed and simulated, and its performance has compared. The polycrystalline MSX-64 PV module has selected in this study, and the impact of partial shading on the PV output power has demonstrated, where multiple peaks can appear in P-V curve with a global one that has to be tracked by the optimal MPPT technique.

Simulation results of the ANFIS and FLC techniques proposed in this work had shown the ability of these controllers to track the global MPP during PSC and the response to weather changes when non-shaded, $25 \%$ and $50 \%$ shaded real weather profile applied to the system. ANFIS controller has shown a dynamic response to weather changes. However, the performance of a conventional P\&O based MPPT has failed to track the global MPP during partial shading and lack response to real weather changes. Consequently, less power extraction has noticed by using this conventional tracking algorithm. These results have shown the performance superiority of the soft computing techniques compared to that of the conventional one, and the drawbacks of conventional P\&O method have confirmed.

Generally, the tradeoff among the terms used to compare the proposed MPPTs as well as the complexity of implementation and the cost is crucial in real application. The next work is to test this system experimentally with the optimization algorithms such as, genetic algorithms (GA), differential evolution, and PSO, as well as the practicality of this system applied to hybrids PV modules $[16,17]$.

\section{SN Applied Sciences}


Funding This study was funded by UTHM-RMC Research Fund (E15501).

\section{Compliance with ethical standards}

Conflict of interest The authors declare that they have no conflict of interest.

\section{References}

1. Liu HD, Lin CH, Pai KJ, Lin YL (2018) A novel photovoltaic system control strategies for improving hill climbing algorithm efficiencies in consideration of radian and load effect. Energy Convers Manag 165:815-826

2. Tey KS, Mekhilef S (2014) Modified incremental conductance MPPT algorithm to mitigate inaccurate responses under fastchanging solar irradiation level. Sol Energy 101:333-342

3. Ishaque K, Salam Z, Taheri H (2011) Modeling and simulation of photovoltaic (PV) system during partial shading based on a two-diode model. Simul Model Pract Theory 19(7):1613-1626

4. Safarudin YM, Priyadi A, Purnomo MH, Pujiantara M (2014) Maximum power point tracking algorithm for photovoltaic system under partial shaded condition by means updating $\beta$ firefly technique. In: 6th international conference on information technology and electrical engineering, pp 1-4

5. Jiang LL, Maskell DL, Patra JC (2013) A novel ant colony optimization-based maximum power point tracking for photovoltaic systems under partially shaded conditions. Energy Build $58: 227-236$

6. Sundareswaran K, Sankar P, Nayak PSR, Simon SP, Palani S (2015) Enhanced energy output from a PV system under partial shaded conditions through artificial bee colony. IEEE Trans Sustain Energy 6:198-209

7. Jumpasri N, Pinsuntia K, Woranetsuttikul K, Nilsakorn T, Khanngern W (2014) Improved particle swarm optimization algorithm using average model on MPPT for partial shading in PV array. In: Proceedings of the 2014 international electronics engineering congress, pp 1-4
8. Sundareswaran K, Vignesh Kumar V, Palani S (2015) Application of a combined particle swarm optimization and perturb and observe method for MPPT in PV systems under partial shading conditions. Renew Energy 75:308-317

9. Gradella Villalva M, Rafael Gazoli J, Ruppert Filho E (2009) Comprehensive approach to modeling and simulation of photovoltaic arrays. IEEE Trans Power Electron 24(5):1198-1208

10. Alik R, Jusoh A, Sutikno T (2016) A review on perturb and observe maximum power point tracking in photovoltaic system. Telecommun Comput Electron Control 13(3):745

11. Elmelegi A, Emad A (2015) Study of different PV systems configurations case study: Aswan utility study of different PV systems configurations case study: Aswan Utility Company. In: 17th international middle east power systems conference

12. Idris I, Robian MS, Mahamad AK, Saon S (2016) Arduino based maximum power point tracking for photovoltaic system. ARPN J Eng Appl Sci 11(14):8805-8809

13. Sadek SM, Fahmy FH, Nafeh AESA, El-Magd MA (2014) Fuzzy P\&O maximum power point tracking algorithm for a stand-alone photovoltaic system feeding hybrid loads. Smart Grid Renew Energy 05(2):19-30

14. Lund H, Mathiesen BV (2008) Comparative analyses of seven technologies to facilitate the integration of fluctuating renewable energy sources. IET Renew Power Gener 3:190-204

15. Belhachat F, Larbes $C$ (2017) Global maximum power point tracking based on ANFIS approach for PV array configurations under partial shading conditions. Renew Sustain Energy Rev 77:875-889

16. Sajid MU, Ali HM (2019) Recent advances in application of nanofluids in heat transfer devices: a critical review. Renew Sustain Energy Rev 103:556-592

17. Shah TR, Ali HM (2019) Application of hybrid nanofluids in solar energy, practical limitations and challenges: a critical review. Sol Energy 183:173-203

Publisher's Note Springer Nature remains neutral with regard to jurisdictional claims in published maps and institutional affiliations. 